\title{
Maximal voluntary contraction as a functional indicator of adult chronic undernutrition
}

\author{
BY M. VAZ, S. THANGAM, A. PRABHU AND P. S. SHETTY* $\dagger$ \\ Nutrition Research Centre, Department of Physiology, St. John's Medical College, Bangalore, India
}

(Received 12 May 1995 - Accepted 10 November 1995)

\begin{abstract}
Maximal voluntary contraction (MVC) using a handgrip dynamometer was assessed in seventy-two young adult males. The subjects were divided into two groups on the basis of a BMI of $18.5 \mathrm{~kg} / \mathrm{m}^{2}$. The subjects with a BMI $<18.5 \mathrm{~kg} / \mathrm{m}^{2}$ ( $n$ 38) were further divided into an underweight (UW; $n$ 20) group and a chronically energy-deficient (CED; $n$ 18) group. The CED subjects had significantly lower MVC (30.1, SD $5.9 \mathrm{~kg}$ ) than either the well-nourished controls (BMI $>18.5 \mathrm{~kg} / \mathrm{m}^{2}: 39.8$, SD $5.8 \mathrm{~kg}$ ) or the underweight group (37.6, SD $4.9 \mathrm{~kg}$ ). The differences between the CED and UW groups persisted even after the MVC were corrected for forearm muscle area and stature. The results suggest that MVC may be a useful functional indicator of nutritional status particularly in differentiating subjects with chronic undernutrition from individuals who are underweight and not undernourished but have similar BMI.
\end{abstract}

Body mass index: Chronic energy deficiency: Handgrip dynamometry: Maximal voluntary contraction

Body mass index (BMI; weight $(\mathrm{kg}) /$ height $\left.(\mathrm{m})^{2}\right)$, in conjunction with indices of energy turnover, has been proposed as a suitable indicator for the classification of chronic energy deficiency (CED) among adults (James et al. 1988). Subsequently it has been shown that an adult BMI of $<18.5 \mathrm{~kg} / \mathrm{m}^{2}$ alone is sufficient for the diagnosis of CED in adults (FerroLuzzi et al. 1992) and that the earlier concerns regarding the potential for misclassification of healthy, very active and thin or underweight individuals as CED was largely unwarranted. A low BMI in an adult is indicative of a reduction in body energy stores. This reduction manifests as a decrease in fat mass as well as lean body mass including muscle. Studies from our laboratory have shown that individuals with BMI $<18.5 \mathrm{~kg} / \mathrm{m}^{2}$ can be subdivided into two groups, i.e. those who are chronically undernourished or CED and those who are underweight (UW). UW subjects in general have characteristics that are similar to those of well-nourished subjects (WN) in terms of their daily energy intakes (Kurpad et al. 1989a), metabolic characteristics (Kurpad et al. 1989b; Soares \& Shetty, 1991) and cardiovascular responses (Kulkarni et al. 1988) which are different from those seen in chronically undernourished or CED subjects. Since both UW and CED adults have BMI $<18.5 \mathrm{~kg} / \mathrm{m}^{2}$ it is essential to distinguish between CED and UW subjects using easily measurable physiological or anthropometric variables.

Skeletal muscle function indices have been advocated for the assessment of nutritional status (Nicks \& Fleishman, 1962; Brozek, 1984). Changes in muscle function such as contractility, relaxation rate and endurance may precede body composition changes and may help detect functional impairment at subclinical levels (Lopes et al. 1982). Muscle function as measured by maximal momentary grip strength has been used as an indicator of pre-operative nutritional status capable of predicting the likelihood of complications

* Present address: Human Nutrition Unit, Department of Public Health and Policy, London School of Hygiene and Tropical Medicine, 2 Taviton Street, London WCIH 0BT.

$\dagger$ For reprints. 
after gastrointestinal surgery (Klidjian et al. 1980, 1982). Muscle function changes have also been assessed by measuring the strength of contraction of the abductor pollicis during electrode stimulation in patients on diets designed to alter body weight and composition (Lopes et al. 1982; Russell et al. 1983b). In order to be truly useful, however, muscle function indices should not merely reflect anthropometry but should also be able to distinguish between anthropometrically similar groups who may have different nutritional states as is the case between individuals who are UW and those who are CED. The present study was designed to measure and compare one index of muscle function (maximal voluntary contraction; MVC) using a handgrip dynamometer, in WN, UW and CED subjects and to evaluate the usefulness of muscle function in distinguishing UW from undernourished individuals who may have similar BMI.

\section{MATERIALS AND METHODS}

Subjects

A total of seventy-two healthy, adult male subjects between the ages of 18 and 35 years were studied after obtaining fully informed consent. These were divided into two groups on the basis of their BMI: $>18.5 \mathrm{~kg} / \mathrm{m}^{2}(n 34)$ and $<18.5 \mathrm{~kg} / \mathrm{m}^{2}$ ( $n$ 38). The group with BMI $<18.5 \mathrm{~kg} / \mathrm{m}^{2}$ was further subdivided into an UW group $(n 20)$ and a CED group $\left(n\right.$ 18). The WN group (BMI $>18.5 \mathrm{~kg} / \mathrm{m}^{2}$ ) and the UW group were recruited from among the staff and students of the Medical College while the undernourished or CED group was studied at a rurally-based community hospital and consisted largely of rural, agricultural labourers. The UW and CED groups were differentiated on the basis of their socioeconomic status (Pareek \& Trivedi, 1964; Kuppuswamy, 1984) and short stature; the latter probably indicative of undernutrition since childhood (Waterlow, 1988).

\section{Anthropometry}

All subjects underwent a detailed anthropometric assessment that included height $(\mathrm{m})$ and weight $(\mathrm{kg})$ and mid-upper-arm circumference (MAC). Skinfold measurements were obtained from four sites, i.e. triceps, biceps, subscapular and suprailiac, on the same side of the body with the subject standing, using Holtain (Crymmych, Dyfed) skinfold calipers. Percentage fat and fat-free mass (FFM) were estimated from the sum of four skinfolds using the age- and sex-specific equations of Durnin \& Womersley (1974). In addition maximal forearm circumference (FAMC) was also determined and the forearm muscle area (FAMA) calculated as described for the arm (Heymsfield et al. 1979). Muscle mass was derived from corrected arm muscle area (CAMA) using the equation of Heymsfield $e t$ al. (1982).

\section{Maximal voluntary contraction}

MVC were obtained on both the dominant and non-dominant sides using a Harpenden handgrip dynamometer (CMS Weighing Equipment Ltd, London), with the arm by the side of the body and the forearm stretched to an angle of $90^{\circ}$. Three measurements were taken at intervals of at least $1 \mathrm{~min}$. The highest of the three measurements was taken as the MVC. For the purpose of analysis MVC are expressed in absolute terms as well as corrected for FAMA and for stature.

\section{Statistical analysis and ethical approval}

All data were analysed for statistical significance between the two BMI groups ( $>18.5$ and $<18.5 \mathrm{~kg} / \mathrm{m}^{2}$ ) using an independent $t$ test. In addition the data were analysed for differences between WN, UW and CED groups using a one-way ANOVA with multiple 
Table 1. A comparison of anthropometric characteristics of well-nourished $(W N)$, underweight $(U W)$ and chronically energy-deficient (CED) subjects $\ddagger$

(Mean values and standard deviations)

\begin{tabular}{|c|c|c|c|c|c|c|c|c|}
\hline & \multicolumn{2}{|c|}{$\begin{array}{c}\text { BMI } \\
>18 \cdot 5 \mathrm{~kg} / \mathrm{m}^{2} \\
(\mathrm{WN} ; n 34)\end{array}$} & \multicolumn{2}{|c|}{$\begin{array}{c}\text { BMI } \\
<18 \cdot 5 \mathrm{~kg} / \mathrm{m}^{2} \\
\text { (pooled; } n \text { 38) }\end{array}$} & \multicolumn{2}{|c|}{ UW (n 20) } & \multicolumn{2}{|c|}{ CED $(n$ 18) } \\
\hline & Mean & SD & Mean & $\mathrm{SD}$ & Mean & SD & Mean & SD \\
\hline BMI $\left(\mathrm{kg} / \mathrm{m}^{2}\right)$ & $20 \cdot 7$ & $1 \cdot 7$ & $17 \cdot 1^{*}$ & $1 \cdot 0$ & $17 \cdot 3^{*}$ & $1 \cdot 2$ & $16 \cdot 9 *$ & 0.8 \\
\hline Height (m) & 1.722 & $0-054$ & $1 \cdot 683^{*}$ & 0.066 & 1.718 & 0.062 & $1.641^{*} \dagger$ & 0.045 \\
\hline Weight (kg) & $61 \cdot 2$ & $7 \cdot 5$ & $48 \cdot 6^{*}$ & $4 \cdot 8$ & $51 \cdot 1^{*}$ & $4 \cdot 3$ & $45 \cdot 6^{*+}$ & $3 \cdot 4$ \\
\hline $\operatorname{MAC}(\mathrm{cm})$ & $27 \cdot 4$ & $2 \cdot 3$ & $24 \cdot 2^{*}$ & 1.6 & $24 \cdot 6^{*}$ & $1 \cdot 3$ & $23 \cdot 4^{*}$ & 1.5 \\
\hline $\mathrm{CAMA}\left(\mathrm{cm}^{2}\right)$ & $35 \cdot 8$ & 6.9 & $28 \cdot 9 *$ & $5 \cdot 1$ & $28 \cdot 8 *$ & $4 \cdot 8$ & $28 \cdot 3^{*}$ & 4.9 \\
\hline Muscle mass (kg) & $20 \cdot 7$ & $2 \cdot 9$ & $17 \cdot 5^{*}$ & $2 \cdot 4$ & $17 \cdot 6^{*}$ & $2 \cdot 4$ & $17 \cdot 1^{*}$ & $2 \cdot 3$ \\
\hline Body fat $(\%)$ & $18 \cdot 1$ & $5 \cdot 3$ & $11 \cdot 4^{*}$ & $2 \cdot 7$ & $12 \cdot 4^{*}$ & $2 \cdot 6$ & $10-2^{*}$ & $2 \cdot 5$ \\
\hline FFM (kg) & $49 \cdot 9$ & $4 \cdot 9$ & $43 \cdot 0^{*}$ & 3.8 & $44 \cdot 7^{*}$ & $3 \cdot 6$ & $40 \cdot 7^{*+}$ & $2 \cdot 6$ \\
\hline
\end{tabular}

MAC, mid-upper-arm circumference; CAMA, corrected arm muscle area; FFM, fat-free mass.

* Mean values were significantly different from those for WN controls, $P<0.05$.

$\dagger$ Mean values were significantly different from those for UW subjects, $P<0.05$.

¥ Differences between WN controls and the pooled data for BMI $<18 \cdot 5 \mathrm{~kg} / \mathrm{m}^{2}$ were assessed by independent $t$ test; differences between WN controls, UW and CED subjects were assessed by one-way ANOVA with multiple comparisons by the Scheffé test.

comparisons (Scheffé), results being considered significant at $P<0.05$. All results are expressed as means and standard deviations.

The experimental protocol was approved by the Human Investigation and Ethical Committee of the Medical College and fully informed consent was obtained from each subject who participated in the study.

\section{RESULTS}

Comparison of anthropometric and forearm characteristics across the study groups A comparison of the anthropometric differences between the various study groups is summarized in Table 1. The CED group had significantly lower height, weight, fat mass and FFM than the WN controls, and was also significantly different from the UW group in all of these variables. MAC, CAMA and muscle mass were significantly lower in both UW and CED groups than in the WN group and there were no differences between the UW and CED groups (Table 1). FAMC and FAMA were comparable in the CED and UW groups for both dominant and non-dominant sides and were significantly lower than the WN controls (Table 2). Measurements taken on the dominant side were significantly higher than the corresponding measurements taken on the non-dominant side within any of the three study groups.

Variability of maximal voluntary contractions and comparison across study groups The interindividual and intraindividual variabilities in MVC were 16.3 and 5.7 respectively. Interindividual variability was higher in the CED group for both dominant and nondominant sides while intraindividual variability was similar across groups. MVC on both dominant and non-dominant sides had similar statistically significant correlations with several anthropometric indices such as FFM $(r 0.66)$, body weight $(r 0.63)$, muscle mass 
Table 2. A comparison of forearm anthropometric characteristics of well-nourished $(W N)$, underweight $(U W)$ and chronically energy-deficient (CED) subjects; the effect of dominance and differences between the study groups

(Mean values and standard deviations)

\begin{tabular}{|c|c|c|c|c|c|c|}
\hline & \multicolumn{2}{|c|}{$\underset{(n 34)}{\text { WN }}$} & \multicolumn{2}{|c|}{$\underset{(n \text { 20) }}{\mathrm{UW}}$} & \multicolumn{2}{|c|}{$\begin{array}{c}\text { CED } \\
(n \text { 18) }\end{array}$} \\
\hline & Mean & SD & Mean & SD & Mean & SD \\
\hline \multicolumn{7}{|l|}{ FAMC } \\
\hline Dominant $\dagger$ & $24 \cdot 2$ & $1 \cdot 5$ & $23 \cdot 0^{*}$ & 0.8 & $22 \cdot 2^{*}$ & 0.8 \\
\hline $\begin{array}{l}\text { Non-dominant } \\
\text { FAMA }\end{array}$ & $23-2$ & 1.4 & $22 \cdot 1^{*}$ & 0.9 & $21 \cdot 7^{*}$ & 0.9 \\
\hline Dominant $\dagger$ & $46 \cdot 7$ & 5.8 & $42 \cdot 1^{*}$ & $3 \cdot 0$ & $39 \cdot 4^{*}$ & $2 \cdot 7$ \\
\hline Non-dominant & $43 \cdot 0$ & $4 \cdot 9$ & $38.8^{*}$ & $3 \cdot 3$ & $37 \cdot 6^{*}$ & $3 \cdot 2$ \\
\hline
\end{tabular}

FAMC, forearm muscle circumference; FAMA, forearm muscle area.

* Mean values were significantly different from those for WN: $P<0.05$.

$\dagger$ The dominant side was significantly $(P<0.05)$ greater than the non-dominant side in all three groups.

Table 3. A comparison of maximal voluntary contraction $(M V C)$ in well-nourished $(W N)$, underweight $(U W)$ and chronically energy-deficient $(C E D)$ subjects

(Mean values and standard deviations)

\begin{tabular}{|c|c|c|c|c|c|c|c|c|}
\hline & \multicolumn{2}{|c|}{$\begin{array}{c}\quad \text { BMI } \\
>18.5 \mathrm{~kg} / \mathrm{m}^{2} \\
(\mathrm{WN} ; n 34)\end{array}$} & \multicolumn{2}{|c|}{$\begin{array}{c}\text { BMI } \\
<18.5 \mathrm{~kg} / \mathrm{m}^{2} \\
\text { (pooled; } n 38 \text { ) }\end{array}$} & \multicolumn{2}{|c|}{ UW $(n 20)$} & \multicolumn{2}{|c|}{ CED $(n 18)$} \\
\hline & Mean & SD & Mean & SD & Mean & SD & Mean & SD \\
\hline \multicolumn{9}{|l|}{ MVC } \\
\hline Dominant & $40 \cdot 1$ & $5 \cdot 3$ & $34 \cdot 6^{*}$ & $7 \cdot 0$ & $38 \cdot 3$ & $5 \cdot 3$ & $30 \cdot 1 *+$ & $6 \cdot 2$ \\
\hline Non-dominant & $39 \cdot 8$ & $5 \cdot 8$ & $34 \cdot 3 *$ & 6.6 & $37 \cdot 6$ & $4 \cdot 9$ & $30 \cdot 1 * \dagger$ & 5.9 \\
\hline \multicolumn{9}{|l|}{ MVC/FAMA } \\
\hline Dominant & $0 \cdot 86$ & $0 \cdot 10$ & 0.83 & $0 \cdot 15$ & 0.91 & $0 \cdot 11$ & $0.74 * \dagger$ & $0 \cdot 15$ \\
\hline Non-dominant & $0.93 \ddagger$ & $0 \cdot 12$ & 0.897 & $0 \cdot 17$ & $0.97 \dagger$ & $0 \cdot 11$ & $0.78 * \dagger$ & $0 \cdot 16$ \\
\hline \multicolumn{9}{|c|}{$\mathrm{MVC} /(\mathrm{FAMA} \times \mathrm{HT})$} \\
\hline Dominant & 0.50 & 0.06 & 0.49 & 0.08 & 0.53 & 0.06 & $0.45 \dagger$ & 0.09 \\
\hline Non-dominant & $0 \cdot 54 \ddagger$ & $0-08$ & $0.53+$ & 0.09 & $0.57 \ddagger$ & 0.07 & $0.48 * \dagger$ & $0 \cdot 10$ \\
\hline
\end{tabular}

FAMA, forearm muscle area; HT, height (m).

* Mean values were significantly different from those for WN: $P<0.05$.

$\uparrow$ Mean values were significantly different from those for UW: $P<0.05$.

$\$$ Mean values were significantly different from those for the dominant arm: $P<0.05$.

( $r$ 0.55) and BMI ( $r$ 0.46). Table 3 highlights the comparative results of the MVC in the three groups. The CED group had significantly lower MVC both in absolute terms as well as when corrected for stature and FAMA than the WN group. This was largely true irrespective of whether the measurements were made on the dominant or non-dominant side. In contrast, the MVC of the UW group were comparable to the MVC of the WN controls despite significant differences in other anthropometric indices (Table 1), and were significantly higher than those of the CED group although the measured forearm anthropometric indices were similar in both groups (Table 2). 


\section{DISCUSSION}

It is important to diagnose the chronically undernourished or energy-deficient (CED) state in a community as well as a clinical set-up. In the community it allows for the description of the overall nutritional status as a necessary measure prior to the formulation of nutritional policy and the introduction and evaluation of intervention programmes (Shetty \& James, 1994). In a clinical situation the CED patient needs to be identified in view of special nutritional requirements (Fernandez et al. 1993), drug-nutrient interactions (Krishnaswamy, 1978) and a possible altered sensitivity to drugs in the undernourished state (Jayarajan \& Shetty, 1987; Kulkarni et al. 1988; Vaz et al. 1992). In addition, the clinician needs to assess prognosis taking into account the undernourished state (Klidjian et al. 1980).

The classification of adult CED is based on the use of BMI and energy turnover as recommended by the International Dietary Energy Consultancy Group working party (James et al. 1988). The determination of energy turnover requires the estimation of daily energy intake or energy expenditure which limits its applicability on an epidemiological scale. It has therefore been suggested that BMI alone be used for the diagnosis of CED in adults (Ferro-Luzzi et al. 1992). However, BMI used alone may be associated with considerable misclassification errors since even the National Centre for Health Statistics data on adults indicate the presence of a reasonable number of underweight but not necessarily undernourished individuals in a community (Abraham et al. 1979).

The results of the present study suggest that MVC may help to delineate the CED state. Methodologically it appears to make little difference whether the dominant or nondominant side is measured in terms of differentiating between groups. MVC was corrected for FAMA in an attempt to express muscle strength per unit muscle mass. If in fact FAMA was a major determinant of handgrip strength it would seem plausible that correcting MVC for FAMA might reduce the differences in MVC between the three groups. This does not, in fact, occur (Table 3) and might be related to the fact that strength of the handgrip involves only a part of the forearm muscle mass; an explanation that may also account for the higher MVC/FAMA in the non-dominant side of all the groups. Since muscle development, and therefore muscle strength, is dependent on the growth of the long bones, the lower MVC in the CED subjects may be attributed to their shorter stature. However, the similar MAC, CAMA and the statistically insignificant differences in FAMA between the UW and CED groups with significant differences in stature do not support this. When MVC were expressed to correct for differences in stature (Ghesquiere \& Eekels, 1984) between the CED group and the rest, the differences between the CED subjects and the other groups persisted despite this correction (Table 3).

MVC has been found to be useful in the assessment of nutritional status, particularly in states of acute weight loss (Lopes et al. 1982) and in evaluating prognosis of nutritionally depleted patients (Klidjian et al. 1980). It has also been shown to be more sensitive to changes in dietary patterns than many traditionally measured nutritional variables (Russell et al. 1983a). On the other hand, however, muscle function may be dissimilar across different muscle groups in the same individual (Lambert, 1965). A drawback in the testing of muscle strength with a dynamometer is the dependence on motivation of the subject to exert maximal effort. It is encouraging that there were no large differences in the intraindividual variability in MVC across groups in the present study suggesting that motivation may not have been a factor contributing to these differences. The interpretation of MVC is also confounded by genetic influences (Reed et al. 1991), the effect of training (Hakkinen et al. 1985) and age (Larsson \& Karlson, 1978). It would therefore be necessary to determine the cut-offs for undernutrition across different age ranges. 
The present study demonstrates that the testing of muscle function, in the form of maximal grip strength, is a simple but useful functional variable that can be used to delineate the undernourished state both at the bedside and in the community and may form a valuable adjunct to BMI.

This study was supported by the Nestlé Foundation, Switzerland. The authors would like to thank Drs A. J. W. Jacob and Mario Soares for their help and useful discussions.

\section{REFERENCES}

Abraham, S., Johnson, C. L. \& Najjar, M. F. (1979). Weight by Height and Age for Adults 18-74 Years. National Centre for Health Statistics. DHEW Publication no. (PHS) 79-1656. Washington, DC: Department of Health, Education and Welfare.

Brozek, J. (1984). The assessment of motor function in adults. In Malnutrition and Behaviour: Assessment of Key Issues. Nestlé Foundation Publication Series vol, 4, pp. 268-279 [J. Brozek and B. Schurch, editors]. Lausanne: Nestlé Foundation.

Durnin, J. V. G. A. \& Womersley, J. (1974). Body fat assessed from total body density and its estimation from skinfold thicknesses: measurements on 481 men and women aged 16 to 72 years. British Journal of Nutrition 32, 77-97.

Fernandez, I. S., Kurpad, A. V., Kilpadi, A. B. \& Shetty, P. S. (1993). Resting energy expenditure and nitrogen losses after surgery in chronically undernourished patients. World Journal of Surgery 17, 80-84.

Ferro-Luzzi, A., Sette, S., Franklin, M. \& James, W. P. T. (1992). A simplified approach of assessing adult chronic energy deficiency. European Journal of Clinical Nutrition 46, 173-176.

Ghesquiere, J. \& Eekels, R. (1984). Fitness of children in Kinshasa. In Children and Sport, pp. 110-127 [J. Ilmarinen and I. Valimaki, editors]. Berlin: Springer Verlag.

Hakkinen, K., Alen, M. \& Komi, P. V. (1985). Changes in isometric force and relaxation-time, electromyographic and muscle fibre characteristics of human skeletal muscle during strength training and detraining. Acta Physiologica Scandinavica 125, 573-585.

Heymsfield, S. B., McManus, C., Smith, J., Stevens, V. \& Nixon, D. W. (1982). Anthropometric measurement of muscle mass: revised equations for calculating bone-free arm muscle area. American Journal of Clinical Nutrition 36, 680-690.

Heymsfield, S. B., Olafson, R. P., Kunter, M. H. \& Nixon, D. W. (1979). A radiographic method for quantifying protein-calorie malnutrition. American Journal of Clinical Nutrition 32, 693-702.

James, W. P. T., Ferro-Luzzi, A. \& Waterlow, J. C. (1988). Definition of chronic energy deficiency in adults. Report of a working party of the international dietary energy consultative group. European Journal of Clinical Nutrition 42, 969-981.

Jayarajan, M. P. \& Shetty, P. S. (1987). Vascular B-adrenoceptor sensitivity of undernourished subjects. British Journal of Nutrition 58, 5-11.

Klidjian, A. M., Archer, T. J., Foster, K. J. \& Karran, S. J. (1982). Detection of dangerous malnutrition. Journal of Parenteral and Enteral Nutrition 6, 119-121.

Klidjian, A. M., Foster, K. J., Kammerling, R. M., Cooper, A. \& Karran, S. J. (1980). Relation of anthropometric and dynamometric variables to serious post-operative complications. British Medical Journal 281, 899-901.

Krishnaswamy, K. (1978). Nutrition and drug metabolism. Indian Journal of Medical Research 68, $109-120$.

Kulkarni, R. N., Kurpad, A. V. \& Shetty, P. S. (1988). Vascular adrenoceptor sensitivity to graded doses of norepinephrine infusions in undernourished subjects. Indian Journal of Medical Research 88, 427-433.

Kuppuswamy, B. (1984). Socio-economic Status Scale (Urban). Delhi: Manasayan.

Kurpad, A. V., Kulkarni, R. N., Sheela, M. L. \& Shetty, P. S. (1989a). Thermogenic responses to graded doses of noradrenaline in undernourished Indian male subjects. British Journal of Nutrition 61, 201-208.

Kurpad, A. V., Kulkarni, R. N. \& Shetty, P. S. (1989 b). Reduced thermoregulatory thermogenesis in undernutrition, European Journal of Clinical Nutrition 43, 27-33.

Lambert, $O$. (1965). The relationship between maximum isometric strength and maximum concentric strength at different speeds. International Federation of Physical Education Bulletin 35, 13-21.

Larsson, L. \& Karlson, J. (1978). Isometric and dynamic endurance as a function of age and skeletal muscle characteristics. Acta Physiologica Scandinavica 104, 129-136.

Lopes, J., Russell, D. McR., Whitwell, J. \& Jeejeebhoy, K. N. (1982). Skeletal muscle function in malnutrition. American Journal of Clinical Nutrition 36, 602-610.

Nicks, D. C. \& Fleishman, E. A. (1962). What does physical fitness measure. A review of factor analytic studies. Education and Psychological Measurement 22, 77-95.

Pareek, U. \& Trivedi, G. (1964). Manual of Socio-Economic Status Scale (Rural). Delhi: Manasayan.

Reed, T., Fabsitz, R. R., Selby, J. V. \& Carmelli, D. (1991). Genetic influences and grip strength norms in the NHLBI twin study males aged 59-69. Annals of Human Biology 18, 425-432. 
Russell, D. McR., Leiter, L. A., Whitwell, J., Marliss, E. B. \& Jeejeebhoy, K. N. (1983a). Skeletal muscle function during hypocaloric diets and fasting: a comparison with standard nutritional assessment parameters. American Journal of Clinical Nutrition 37, 133-138.

Russell, D. McR., Pendergast, P. J., Darby, P. I., Garfinkel, P. E., Whitwell, J. \& Jeejeebhoy, K. N. (1983b). A comparison between muscle function and body composition in anorexia nervosa: the effect of refeeding. American Journal of Clinical Nutrition 38, 229-237.

Shetty, P. S. \& James, W. P. T. (1994). Body Mass Index: A Measure of Chronic Energy Deficiency in Adults. FAO Food and Nutrition Paper. Rome: FAO.

Soares, M. J. \& Shetty, P. S. (1991). Basal metabolic rates and metabolic economy in chronic undernutrition. European Journal of Clinical Nutrition 45, 363-373.

Vaz, M., Jayarajan, M. P., Kulkarni, R. N., Balasubramanyam, A. \& Shetty, P. S. (1992). Parasympathetic tone in chronic energy deficient human subjects. Nutrition Research 12, 613-620.

Waterlow, J. C. (1988). Observations on the variability of man. In Comparative Nutrition, pp. 130-140 [K. L. Blaxter and I. A. Macdonald, editors]. London: John Libbey. 